\title{
Comparative tests of ridging cultivators with active and passive working tools
}

\author{
Andrey Panov ${ }^{1 *}$, Maxim Mosyakov ${ }^{2}$, Stepan Semichev ${ }^{2}$, Valery Plyaka ${ }^{1}$, Nikolay Lylin ${ }^{1}$ and \\ Mikhail Mekhedov ${ }^{1}$ \\ ${ }^{1}$ Russian Timiryazev State Agrarian University; Moscow, Russian Federation \\ ${ }^{2}$ Federal Scientific Agroengineering Center VIM, 5, Moscow, Russian Federation
}

\begin{abstract}
Two types of ridging cultivators for growing potatoes and other vegetables were designed and tested. The first machine GPK-2 has active working tools - rotary drum with straight cutters, passive sweeps on rigid tines, and plates forming ridges. The second machine GD-2 has only passive drought working tools: spring S-shaped tines with sweeps of two forms, disks, and plates forming ridges. Field tests were carried out to determine soil preparation quality and energy consumption indicators of both machines on loamy soils typical for the non-chernozem zone of the Russian Federation. It is advisable to use the indicator of the specific power consumption related to the average diameter of loosened soil clods. Measured specific power per average clod diameter was in range 3.3...4.3 $\mathrm{kW} \times \mathrm{mm}^{-1}$ for the active rotary ridging cultivator, and $2.6 \ldots 3.2 \mathrm{~kW} \times \mathrm{mm}^{-1}$ for the cultivator with passive working tools. The required power for the machine with passive working tools at the maximum possible forward speed is $25 \ldots 35 \%$ lowers than for a rotary machine. Though cutting ridges on the post-planting treatment of loamy soil, rotary tiller supplies better soil crumbling. On inter-row cultivation of light loamy soils, the machine with passive working tools is a preferable solution due to less energy consumption relative to the machine with an active rotary drive.
\end{abstract}

\section{Introduction}

Farmers mainly use technologies for growing potatoes on ridges with $75 \mathrm{~cm}$ row spacing. These technologies usually use pre-planting and post-planting tillage [1], including upper soil layer loosening, weed control, and the formation of ridges [2]. Cultivators, forming ridges, carry out at the same time continuous loosening of the upper soil layer [4], strip tillage of the underlying soil layers along the axis of the rows. Pre-planting soil tillage should ensure its high-quality soil preparation for the development of seedlings [5]. In conditions of insufficient moisture and low humidity, recommended additionally to roll the soil surface.

Optimal design parameters of rotary tilling machines substantiated in researches [6, 7]. Theoretical methods for calculating energy consumption during the operation of combined machines are devoted to works $[8,9]$. One of the main indicators of soil preparation quality

\footnotetext{
*Corresponding author: andreypanov@yahoo.com
} 
for vegetable crops, especially on irrigated lands, is the degree of soil pulverization. Also, reducing energy and fuel consumption is very important to increase design tillage machines [3].

The purpose of this study was to select the best types of working bodies of cultivators for ridge-forming cultivators for soil conditions typical for the central region of the European part of the Russian Federation.

\section{Methods}

Timiryazev State Agrarian University, jointly with Federal Scientific Agro-engineering Center VIM, developed experimental samples of bed-forming cultivators for pre-plant forming seedbeds and ridges when growing potatoes, Jerusalem artichoke, and other vegetables (figures 1 and 2).

It is advisable to compare soil preparation quality and energy consumption indicators of tillage machines by experimental methods $[10,11]$.
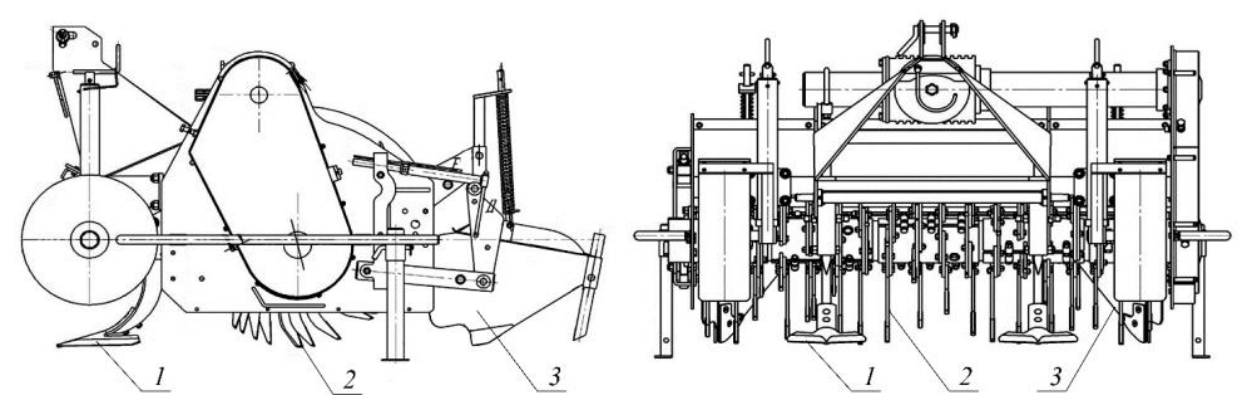

Fig. 1. Rotary cultivator GPK-2 for ridging: 1 are sweeps $150 \mathrm{~mm}$ wide cut; 2 is rotary drum with straight cutters; 3 are ridge forming plates
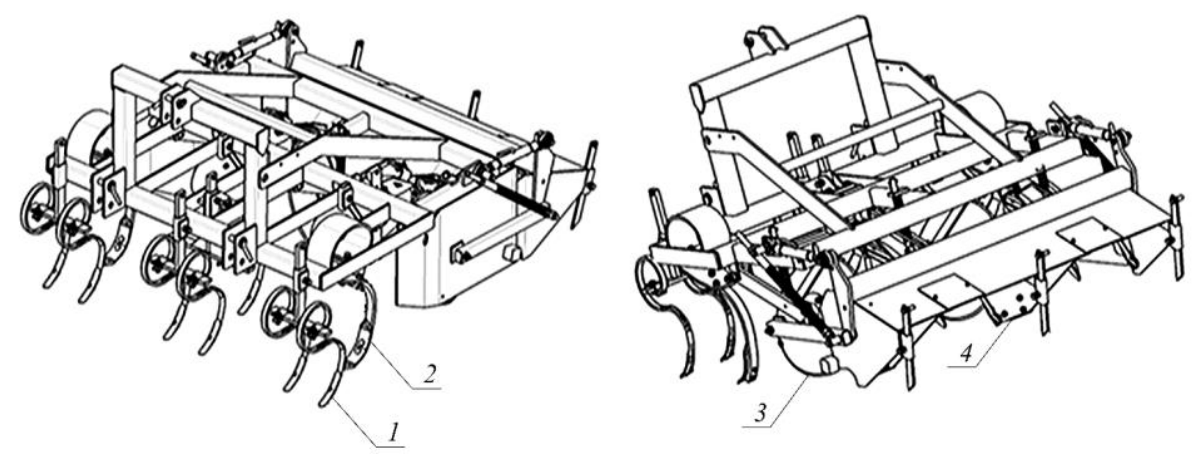

Fig. 2. Tine sweeps - disc cultivator GD-2 for ridging:

1 and 2 are loosening spring tines; 3 and 4 are discs and plates for ridge formation

The mounted rotary cultivator ridge-former GPK-2 can form seedbed in two ridges with tractors with an engine power of more than $60 \mathrm{~kW}$ at a PTO speed of 540 or $1000 \mathrm{~min}^{-1}$. Pre- and post-planting ridging can produce on fields of various configurations with a slope of up to $3^{\circ}$, soil hardness up to $3.0 \mathrm{MPa}$, and absolute soil humidity up to $25 \%$. The cultivator can be equipped with additional working bodies in the form of cultivator paws, rollers, plates for the formation of ridges [12]. 
Continuous soil cultivation with an active rotary drum carried out to a depth of $12 \mathrm{~cm}$. On medium and heavy soils along the axis of the planting crops rows, strip loosening with cultivator tines produced to a depth of $18 \mathrm{~cm}$ [13] within permissible deviation from the set depth for tilling $\pm 1.5 \mathrm{~cm}[14]$.

The mounted cultivator GD-2 has only passive working tools [11] designed for pre-planting and post-planting processing of light and medium soils by strip loosening up to $20 \ldots 25 \mathrm{~cm}$ or chisel to a depth of $35 \mathrm{~cm}$ with two rows of tiny sweeps with a row spacing of $75 \mathrm{~cm}$ with furrow discs and plates forming ridges or ridges.

Field tests were carried out in the fields of the Russian Potato Research Center (Moscow region) and the experimental station of the Timiryazev State Agrarian University on medium and light loamy soils with the following characteristics: even relief and microrelief, soil layer $0 \ldots 15 \mathrm{~cm}$ hardness $0.2 \ldots 0.34 \mathrm{MPa}$, absolute humidity $19 \ldots 22 \%$, postharvest residues - stubble of grain crops.

\section{Results and Discussion}

Agrotechnical and energy indicators of two types of cultivators were evaluated during the formation of ridges after spring planting potatoes with a planter. The cultivators aggregated with MTZ-82 tractor with engine tested preliminarily. According to the certification test, the tractor engine had an operating power of $61.0 \mathrm{~kW}$ and specific fuel consumption of 0.24 $\operatorname{kg}((\mathrm{kW}(\mathrm{h})-1$.

The following parameters were measured and calculated during the field tests: torques on the tractor engine shaft and on the power take-off shaft PTO $(\mathrm{N} \times \mathrm{m})$; cultivator traction resistance $(\mathrm{kN})$; the rotational speed of the engine shaft, tractor driving wheels, and the PTO rotational speed $\left(\mathrm{s}^{-1}\right)$; the path traversed by the unit during the experiment $(\mathrm{m})$ and experience time (s). Relative errors of energy indicators obtained less than 2-3\% according to the standard methods [15].

The quality of soil cultivation and the energy performance of the machines [16] were

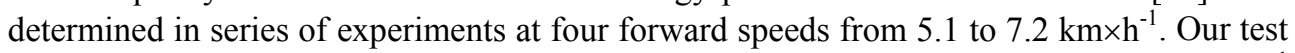
shows that the tractor MTZ-82 engine overloaded at a speed of more than $6.1 \mathrm{~km} \times \mathrm{h}^{-1}$ working with the GPK-2 rotary ridge cultivator.

Both machines satisfied quality requirements adopted in Russia [17]. The presence of clods up to $20 \mathrm{~mm}$ was more than $90 \%$, and there were no clods with a diameter over 50 $\mathrm{mm}$. The height of the formed ridges was $28.5 \ldots 28.6 \mathrm{~cm}$. The width of the ridges was $21 \ldots 22 \mathrm{~cm}$. There was no increase in the content of erosion-hazardous particles with a diameter less than $1 \mathrm{~mm}$ in the $0 . .5 \mathrm{~cm}$ soil layer. The topsoil density in the ridges was $0.85 \ldots 1.1 \mathrm{~g} \times \mathrm{cm}^{-3}$.

The diagram of soil crumbling (distribution of clod sizes in mm by fractions), obtained during the agrotechnical assessment of the compared cultivators GPK-2 and GD-2, is shown in figure 3. 


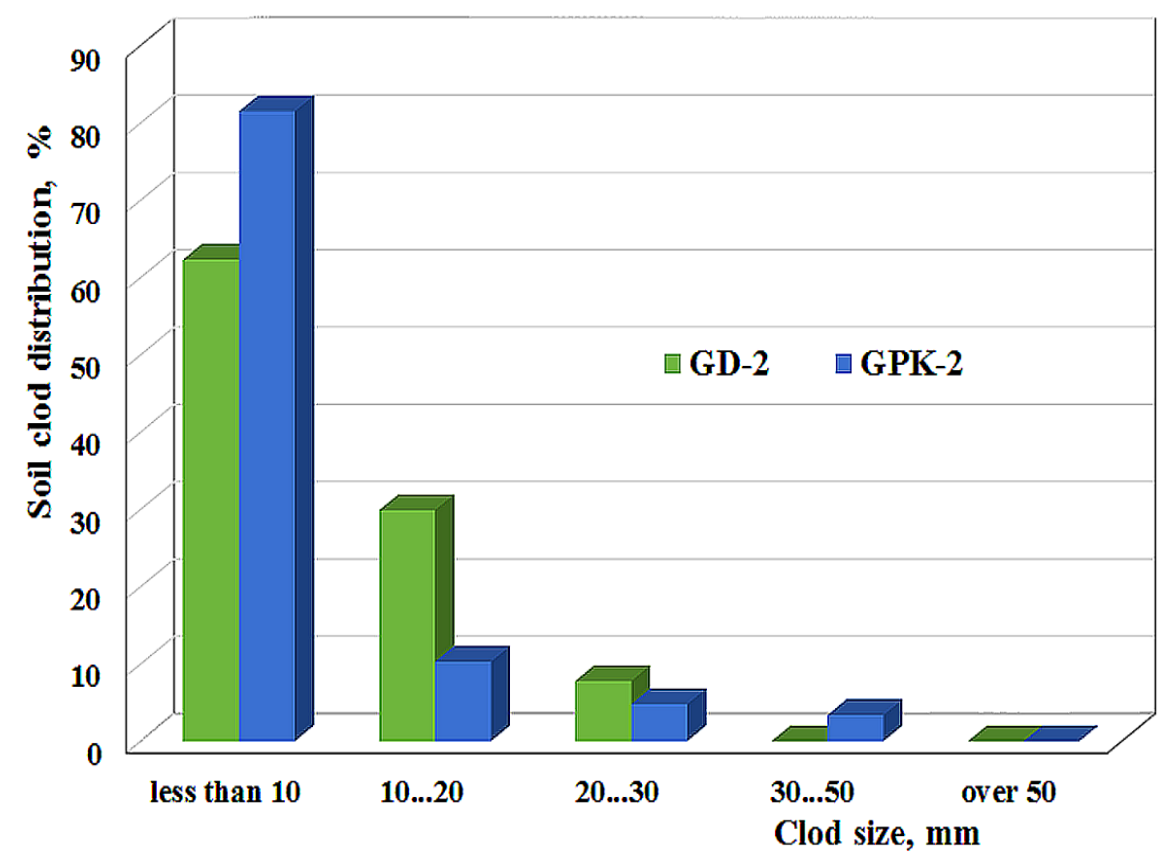

Fig. 3. Soil crumbling diagram for two tested cultivator types

The depth of cultivation with loosening tines for both ridge-formers (with active rotary and with passive disc-tine working bodies) in a series of experiments varied from $8 \mathrm{~cm}$ to $16 \mathrm{~cm}$ within a step of $2 \mathrm{~cm}$.

An example of the experimental determination, how the power $N(\mathrm{~kW})$ required for the unit operation dependent on two main parameters: the sweeps depth $h(\mathrm{~cm})$ and the machine forward speed $v\left(\mathrm{~m} \times \mathrm{s}^{-1}\right)$, is shown in figure 4 .

To establish a functional connection $N=f(v, h)$ the linear regression equation was used in the form $N=b_{0}+b_{1} \times v+b_{2} \times h$. The following regression equations were obtained for the power required for the tested cultivators after processing the results of 16 observations of experiments (table).

Table. Dependencies of required energy $N(\mathrm{~kW})$ on forward velocity $v\left(\mathrm{~m} \times \mathrm{s}^{-1}\right)$ and sweeps working depth $h(\mathrm{~cm})$

\begin{tabular}{|c|c|c|c|}
\hline Machine type & Regression equation & Multiple $R$ & $R^{2}$ \\
\hline GPK-2 rotary cultivator & $N=29.44+6.35 \times v+1.0 \times h$ & 0.70 & 0.58 \\
\hline GD-2 sweeps-disks cultivator & $N=21.27+4.83 \times v+0.95 \times h$ & 0.71 & 0.63 \\
\hline
\end{tabular}

The regression coefficients $b_{0}, b_{1}$, and $b_{2}$ for the certain field conditions are determined through the least squares method. The dispersion values for all coefficients were calculated, and the trustful interval through the Student's criterion was estimated. Coefficients not meeting the 0.95 value level excluded from the equation. The adequacy of the regression was tested by the Fisher's criterion. 


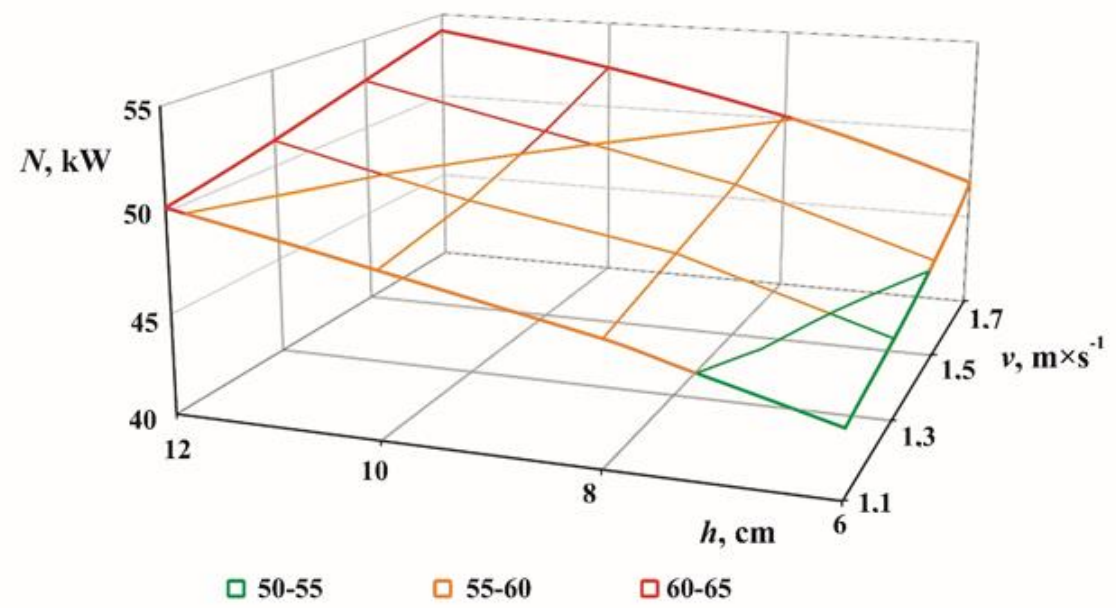

Fig. 4. Dependence of power consumption $(N, \mathrm{~kW})$ on sweeps depth $(h, \mathrm{~cm})$ and forward speed $(v$, $\mathrm{m} \times \mathrm{s}^{-1}$ ) for rotary ridging cultivator GPK-2

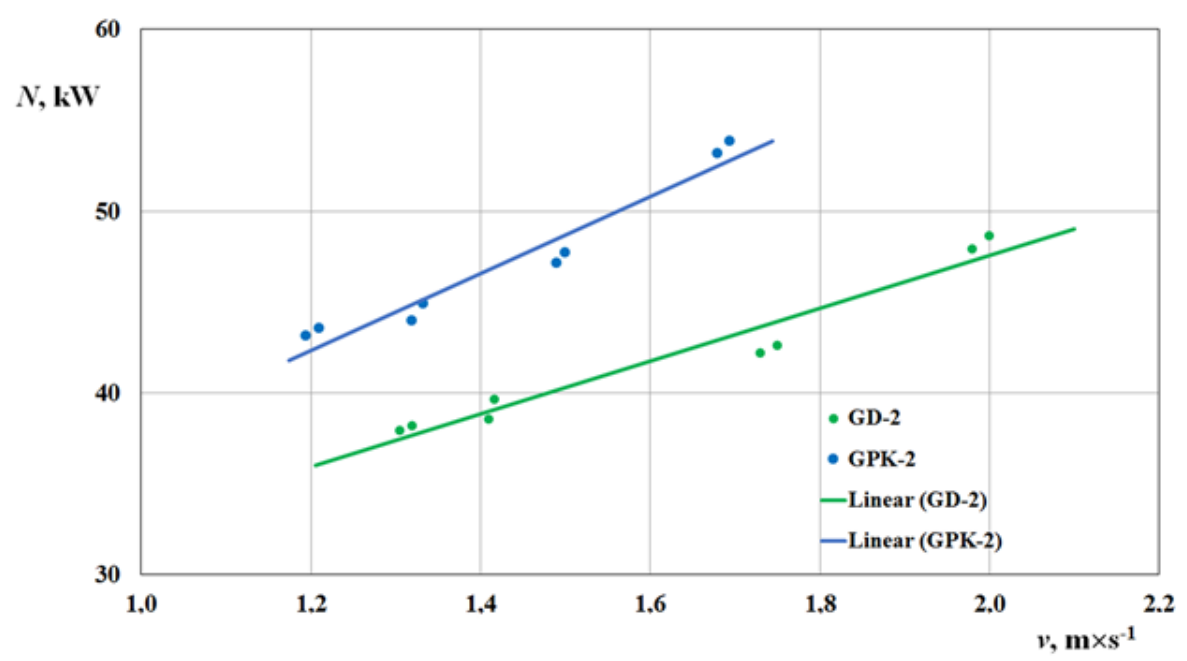

Fig. 5. Power requirements for compared ridging cultivators

It was found that the maximum power consumption $N(\mathrm{~kW})$ unit with sweeps and disks passive tools cultivator, when performing a technological process at speed $1.3 \ldots 2.0 \mathrm{~m} \times \mathrm{s}^{-1}$ was $38 \ldots 49 \mathrm{~kW}$ (figure 5). Maximum power consumption of unit with active rotary cultivator GPK-2 in the forward speed range $1.2 \ldots 1.7 \mathrm{~m} \times \mathrm{s}^{-1}$ was $43 \ldots 54 \mathrm{~kW}$ [14-24].

Power consumption measurements shown in figures 5 и 6 correspond to the working depth of the loosening cultivator tines in the range from 11.9 to $12.7 \mathrm{~cm}$. The maximal forward speed of tractor MTZ-82 with cultivator GPK-2 was $5.4 \mathrm{~km} \times \mathrm{h}^{-1}$, with cultivator GD-2 $-7.2 \mathrm{~km} \times \mathrm{h}^{-1}$. 


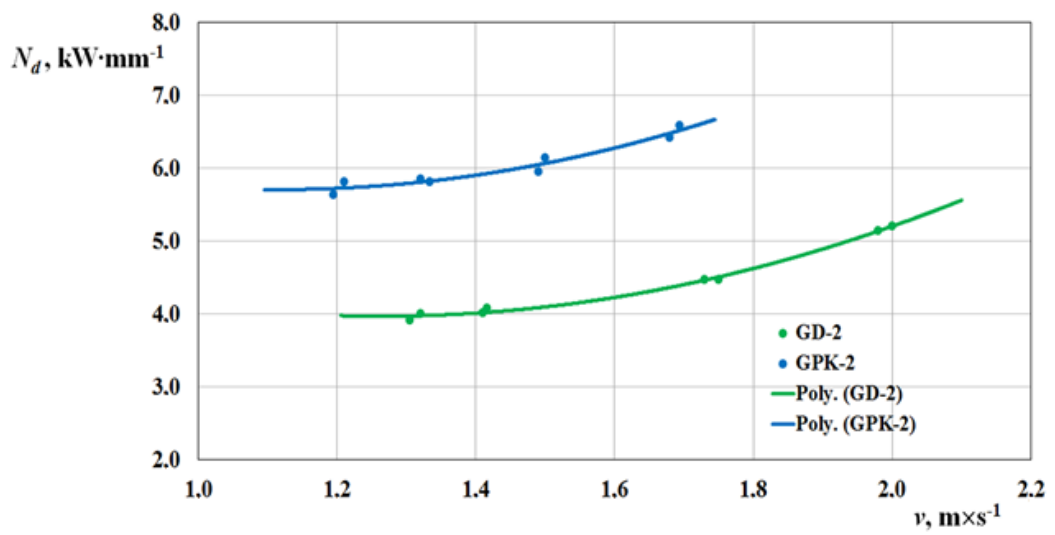

Fig. 6. Specific power consumption per average clod diameter for compared cultivators

We have a significant increase of tillage energy requirements with forward speed raising for a rotary cultivator with active working tools we explained by an increase in cutting forces, and for a cultivator with passive sweeps and disk working tools an increase in traction resistance $[9,10]$.

\section{Conclusions}

Studies of 2-row ridge-forming cultivators with active and passive working tools, carried out on typical soils of Russia Central European part, allow us to conclude that their quality indicators fully meet the agrotechnical requirements.

Cultivator with active working tools demonstrated higher soil preparation quality because the design of the active rotary ridge-former allows controlling the soil crumbling degree by changing the machine forward speed. Though on post-planting treatment of loamy soil, rotary tiller supplies better soil crumbling.

The required powers for the cultivator with passive working tools at the maximum possible forward speed is $25 . .35 \%$ lower than for rotary machine. Measured indicator of specific power per average clod diameter was obtained in range $3.3 \ldots 4.3 \mathrm{~kW} \times \mathrm{mm}^{-1}-$ for the active rotary ridging cultivator, and $2.6 \ldots 3.2 \mathrm{~kW} \times \mathrm{mm}^{-1}-$ for the ridging cultivator with passive sweeps and discs working tools. On inter-row cultivation of loamy soils, the machine with passive working tools is a preferable solution due to less energy consumption relative to the machine with an active rotary drive.

One of the directions for further research is to determine the possibility of using the rotary cultivator on continuous pre-planting soil cultivation for potatoes on heavy loamy soils to replace the chisel cultivator and a 2-row disc harrow, aggregated with tractors with engine power over $110 \mathrm{~kW}$. Preliminary calculations show that at the same time, due to the combination of deep loosening and rotary tilling can increase productivity.

\section{Funding statement}

This work was carried out with the support of the Russian Federation and Belarus government project entitled "Innovative production of potatoes and Jerusalem artichoke."

\section{Acknowledgments}

We thank all our colleagues in the Russian Potato Research Centre and Vladimir machine test station, who worked with us on field tests described in this paper. 


\section{References}

1. Ghazavi M.A. Hosseinzadeh B and Lotfalian A. Evaluating Physical Properties of Potato by a Combined Tillage Machine, Nature and Science 8 (11), pp. 66-70, (2010)

2. Hosokawa H., Adachi K., Itoh K and Matsuzaki M. Rotary Tilling and Ridge-Making Methods for Heavy Clay Soil Japan Agricultural Research Quarterly: JARQ, 35 (4) pp. 255-61, (2001)

3. Lobachevsky Y.P. Ploughing quality and energy consumption depending on plough bodies type, IOP Conference Series: Materials Science and Engineering 1030, 012154, (2021)

4. Yatsuk E P et al Rotary Soil Working Machines: Construction, Calculation and Design. U.S. Department of Agriculture and the National Science Foundation p 256. (1981)

5. Manian R K Kathirvel and Nagaiyan V Development and Evaluation of Combination Tillage-Bed Furrow-Former AMA, Agricultural Mechanization in Asia, Africa and Latin America 30 (4) pp 22-29, (1999)

6. Kheiralla A F Yahya A Zohadie M and Ishak W Modelling of power and energy requirements for tillage implements operating in Serdang sandy clay loam, Malaysia Soil and Tillage Research 78(1) pp 21-34, (2004)

7. Zhang G Zhang Z Xiao M Bartos P and Bohata A (2019) Soil-cutting simulation and parameter optimization of rotary blade's three-axis resistances by response surface method Computers and Electronics in Agriculture 164104902

8. Saimbhi V S Wadhwa D S and Grewal P S Development of a Rotary Tiller Blade Using Three-Dimensional Computer Graphics Biosystems Engineering 89 (1) pp 47 58, (2004)

9. Ahmadi Iman A Torque Calculator for Rotary Tiller Using the Laws of Classical Mechanics Soil and Tillage Research 165 pp 137-43, (2017)

10. Ahmadi, Iman A Power Estimator for an Integrated Active-Passive Tillage Machine Using the Laws of Classical Mechanics Soil and Tillage Research 171 pp 1-8, (2017)

11. Weise G (1993) Active and Passive Elements of a Combined Tillage Machine: Interaction, Draught Requirement and Energy Consumption Journal of Agricultural Engineering Research 56 (4) 287-99

12. IMAC S.r.l. Access mode:: http://www.imac-rondelli.it/eng/ridge-formers.html (Access date 25.02.2021)

13. Panov A I et al (2020) Agrotechnical and energy assessment of ridgers and seedbed formers Agricultural Engineering 5 (99) pp 4-9 (In Rus.)

14. Gill W R Vanden Berg G E Soil Dynamics in Tillage and Traction. Agriculture Handbook. U.S. Department of Agriculture p 511. (1967)

15. Prathuang Usaborisut Kittikhun Prasertkan (2019) Specific energy requirements and soil pulverization of a combined tillage implement Heliyon Vol 5 Issue 11

16. Behera A Raheman H and Thomas E V (2021) A Comparative Study on Tillage Performance of Rota-Cultivator (a Passive - Active Combination Tillage Implement) with Rotavator (an Active Tillage Implement) Soil and Tillage Research 207

17. Tarverdyan A P Sargsyan S F and Altunyan A V (2017) Investigation results of kinematic and dynamic indicators of tiller with vertical rotation axis in orchards soil cultivation Annals of Agrarian Science 15 (2) pp 163-168

18. Kazuaki H Takashi K Takayuki K Relationship between Required Power and PTO Speed in Rotary Tiller IFAC Proceedings Volumes, Vol 46 Issue 4 pp 141-146. (2013)

19. Matin M A Fielke J M and Desbiolles J M A Torque and energy characteristics for strip-tillage cultivation when cutting furrows using three designs of rotary blade 
Biosystems Engineering 129 pp 329-340. (2015)

20. Anpat R M and Raheman H Investigations on Power Requirement of Active-Passive Combination Tillage Implement Engineering in Agriculture, Environment and Food 10 (1) pp 4-13. (2017)

21. Rakhmonov S., Umurzakov U., Rakhmonov K., Bozarov I., Karamatov O. Land use and land cover change in Khorezm, Uzbekistan. E3S Web of Conferences, 227, 01002, (2021)

22. Umurzakov U., Mamatov F., Aldoshin N., Mirzaev B. Exploration of tillage technologies in the Republic of Uzbekistan, IOP Conference Series, Earth and Environmental Science, 614(1), 012168, (2020)

23. Umurzakov U., and Djuraev B. Prediction of prices for agricultural products through markov chain model, International Journal of Psychosocial Rehabilitation, 24(3), pp. 293-303, (2020)

24. Umurzakov U., Mirzaev B., Salahodjaev R., Isaeva A., and Tosheva S. Energy consumption and economic growth: Evidence from post-communist countries. International Journal of Energy Economics and Policy, 10(6), pp. 59-65, (2020) 